\title{
Detection of positive selection in the major capsid protein VP60 of the rabbit haemorrhagic disease virus (RHDV)
}

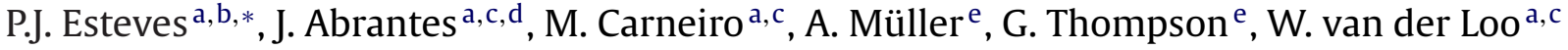 \\ a CIBIO-UP, Centro de Investigação em Biodiversidade e Recursos Genéticos, Universidade do Porto, Campus Agrário de Vairão, Vairão, Portugal \\ b CITS, Centro de Investigação em Tecnologias da Saúde, ISPN, CESPU, Gandra, Portugal \\ c Departamento de Zoologia e Antropologia, Faculdade de Ciências da Universidade do Porto, Porto, Portugal \\ d INSERM U601, Institut de Biologie, Nantes, France \\ e ICBAS/UMIB/UP, Instituto de Ciências Biomédicas de Abel Salazar, Porto, Portugal
}

\section{A R T I C L E I N F O}

\section{Article history:}

Received 29 May 2008

Received in revised form 23 July 2008

Accepted 31 July 2008

Available online 17 September 2008

\section{Keywords:}

Rabbit haemorrhagic disease virus

Positive selection

European rabbit

Major capsid protein VP60

\begin{abstract}
A B S T R A C T
Mutations were analysed in the major capsid protein VP60 of the rabbit haemorrhagic disease virus (RHDV), a calicivirus responsible for high mortality rates in both wild and domestic European rabbits (Oryctolagus cuniculus). Likelihood of positive selection was estimated using the PAML software applied to 43 non-identical complete sequences of the major capsid protein. Three codons showed signs of positive selection (with posterior probabilities over 95\%), one of them is located in the region containing the major antigenic determinants (region E). The presence of positively selected codons (PSCs) in other regions may suggest the existence of other antigenic regions on the major capsid protein that stimulate protective immune responses. At all the 3 PSCs, variation contributes to putative N-glycosylation sites of the protein. An N-glycosylation site is deleted in the non-pathogenic strain RCV. Some of the substitutions at PSCs may alter the polarity and the charge of the protein with possible implications in the protein structure and host interaction. The detection of PSCs should allow a better understanding of the interaction between RHDV and the rabbit immune system.
\end{abstract}

(c) 2008 Elsevier B.V. All rights reserved.

\section{Introduction}

Rabbit haemorrhagic disease (RHD) is a highly contagious disease, characterised by high morbidity and high mortality in both wild and domestic adult rabbits (Oryctolagus cuniculus), whereas rabbits below the age of 2 months usually survive infection(Ferreira et al., 2004; Xu and Chen, 1989). The disease is caused by rabbit haemorrhagic disease virus (RHDV), a member of the genus Lagovirus of the family Caliciviridae (Parra and Prieto, 1990). RHDV is a non-enveloped positive-sense single-stranded RNA virus with a genome of about $7.5 \mathrm{~kb}$ and a sub-genomic RNA of $2.2 \mathrm{~kb}$. There are two open reading frames (ORFs), ORF1 and ORF2. The former encodes a polyprotein which is cleaved into non-structural components (including a helicase, a protease and the RNA-dependent

\footnotetext{
* Corresponding author at: CIBIO-UP, Centro de Investigação em Biodiversidade e Recursos Genéticos, Universidade do Porto, Campus Agrário de Vairão, Rua Padre Armando Quintas, 4485-661 Vairão, Portugal. Tel.: +351 252660 406; fax: +351252661780

E-mail addresses: pjesteves@mail.icav.up.pt (P.J. Esteves), jabrantes@mail.icav.up.pt (J. Abrantes),miguel.carneiro@mail.icav.up.pt (M. Carneiro), amuller@mail.icav.up.pt (A. Müller),gat1@mail.icav.up.pt (G. Thompson),wvdloo@mail.icav.up.pt (W. van der Loo).
}

RNA-polymerase) and the major structural protein, i.e., the capsid VP60. ORF2 encodes VP10, a basic protein present in small amounts in virions (Thiel and Konig, 1999). The capsid protein VP60 is the main target of the host immune defence against RHDV, and plays an important role in virus diagnosis and vaccine design. In common with other caliciviruses, the RHDV capsid is composed of two main domains, a shell $(\mathrm{S})$ domain formed by the $\mathrm{N}$-terminal part of the protein and a protrusion $(\mathrm{P})$ domain formed by the $\mathrm{C}$-terminal part. The latter can be subdivided into two subdomains, P1 and P2. Six distinct regions (A to $F$ ) can be distinguished in the protein. The $C$ and $\mathrm{E}$ regions are located in the exposed P2 subdomain and show the highest degree of genetic variation (Neill, 1992).

Phylogenetic analyses based on the region E of the RHDV VP60, although not consensual, showed that the phylogenetic clustering of RHDV strains is more correlated with the year of isolation of the strain than to the geographic location (Forrester et al., 2006; Le Gall et al., 1998; Le Gall-Reculé et al., 2003; Moss et al., 2002; Nowotny et al., 1997). Recently, recombination within the VP60 gene was described (Abrantes et al., 2008; Forrester et al., 2008). It is therefore possible that by analyzing only parts of the major capsid protein a number of recombinant strains go undetected in phylogenetic studies. Recombination might be one of the obstacles to efficient RHD control. 
Analyses of samples collected in several European countries before the first documented RHDV outbreak (in China in 1984) revealed the presence of anti-RHDV antibodies in wild and domestic rabbits (Forrester et al., 2006; Moss et al., 2002; O'Keefe et al., 1999; Rodák et al., 1990). This suggests the existence of precirculating non-pathogenic virus strains related to RHDV. However, the European rabbit populations appeared not to be entirely protected, because the first recorded outbreaks were highly lethal. The hypothesis that RHDV can circulate among rabbits without causing disease was further supported by the identification of nonpathogenic strains (Capucci et al., 1996; Forrester et al., 2003, 2007; Zheng et al., 2002). Nevertheless, to date no differences have been found that could explain the switch between avirulent and virulent RHDV strains (Capucci et al., 1996; Forrester et al., 2003, 2007; Moss et al., 2002). Thus, knowledge of protein regions under positive selection pressure may help understanding the mechanisms that govern RHDV virulence, pathogenesis and RHD epidemiology. Here we report codons of the major capsid protein VP60 that seem to be under positive selection.

\section{Methods}

All available complete sequences of the major capsid protein VP60 from pathogenic strains were retrieved from GenBank (the accession number, country of origin, strain name and year of isolation of the 43 sequences used are listed in Table 1) and were aligned using the BioEdit software version 7.0.5.3 (Hall, 1999). The following strains were excluded from the analysis since they were shown to be recombinants (Abrantes et al., 2008; Forrester et al., 2008): Hartmannsdorf (GenBank accession number Y15425); Czech V351 (GenBank accession number U54983); Mexico (GenBank accession number AF295785); China 1984 (GenBank accession number AF402614) and France 00-08 (GenBank accession number AJ319594). No evidence of recombination was found for the remaining strains used (data not shown).

In order to better understand the biology of the rabbit haemorrhagic disease and considering the immunogenicity properties of the capsid protein VP60, we hypothesized that substitutions in this region, particularly sites under adaptive molecular evolution, might play a role in the ongoing genetic conflict between host and parasite. Under neutrality, the expected ratio $(\omega)$ of non-synonymous $\left(d_{\mathrm{N}}\right)$ to synonymous $\left(d_{\mathrm{S}}\right)$ substitutions in a gene is one and significant deviations from this value can be interpreted as evidence of either positive $(\omega>1)$ or purifying selection $(\omega<1)$. However, this approach is highly conservative. Here, detection of positive selection was performed using PAML (Yang, 1997). This maximum likelihood (ML) method instead of averaging $\omega$ across the gene uses codon-based models that allow heterogeneity in $d_{\mathrm{N}} / d_{\mathrm{S}}$ among codons in a phylogenetic context, allowing detection of recurrent positive selection occurring only in small portion of a gene. This likelihood-based evolutionary method has been successful applied in the detection of codon-specific positive selection in viruses (e.g. Lemey et al., 2005; Ross and Rodrigo, 2002). We compared the fit of two nested site specific models to the data - a neutral model that does not admit positive selection $(\omega \leq 1)$ and an alternative model that admits positive selection $(\omega>1)$. We compared models M0 to M3, M1a to M2a, M7 to M8 and M8a to M8. In the first comparison, the model M0 assumes a constant $\omega$ ratio across the genes whereas M3 assumes different proportions of discrete classes of sites with different $\omega$ ratios. In the second comparison the null model M1a (neutral/purifying model), was formulated to allow only two site classes for $\omega$ : the conserved category with $0<\omega<1$ and the neutral category with $\omega=1$. The alternative model, M2a (positive selection
Table 1

GenBank accession number, country of origin, strain name and year of isolation of the 43 RHDV VP60 complete and pathogenic sequences used in the study

\begin{tabular}{|c|c|}
\hline GenBank accession number & Country_strain/year \\
\hline AF258618 & EUA/2000 \\
\hline AF453761 & China_tp \\
\hline AJ006019 & UK_Rainham/1993 \\
\hline AJ302016 & France/1999 \\
\hline AJ303106 & France/2000 \\
\hline AJ495856 & France $/ 2000$ \\
\hline AJ535092 & France/1995 \\
\hline AJ535094 & France/1995 \\
\hline AJ969628 & France/2003 \\
\hline AM085133 & France_05-01/2005 \\
\hline AY269825 & China/1985 \\
\hline AY523410 & China_CD \\
\hline AY926883 & Ireland_12/2001 \\
\hline AY928268 & Ireland_01/2001 \\
\hline AY928269 & Ireland \\
\hline DQ069280 & China/2005 \\
\hline DQ069281 & China/2005 \\
\hline DQ069282 & China/2005 \\
\hline DQ189077 & Bahrain20/01 \\
\hline DQ189078 & Saudi Arabia/1996 \\
\hline DQ205345 & China/1997 \\
\hline DQ280493 & China_whnrh \\
\hline DQ530363 & China_YL \\
\hline DQ841708 & Cuba/2004 \\
\hline EF363035 & UK_Ramsey Island/2000 \\
\hline EU003578 & USA_IN-05/2005 \\
\hline EU003579 & Italy/1990 \\
\hline EU003580 & South Korea/1990 \\
\hline EU003581 & USA_NY-01/2001 \\
\hline EU003582 & USA_UT-01/2001 \\
\hline L48547 & Spain_MC-89/1989 \\
\hline M67473 & Germany_FRG/1989 \\
\hline RHU49726 & France/1988 \\
\hline X87607 & Italy/1989 \\
\hline Y15424 & Germany_Frankfurt/1996 \\
\hline Y15426 & Germany_Meiningen/1993 \\
\hline Y15427 & Germany_Wriezen/1996 \\
\hline Y15440 & Germany_Eisenhüttenstadt/1989 \\
\hline Y15441 & Germany_Hagenow/1990 \\
\hline Y15442 & Germany_Triptis/1996 \\
\hline Z24757 & Spain_AST/1989 \\
\hline Z29514 & France/1989 \\
\hline Z49271 & Spain_AST/1989 \\
\hline
\end{tabular}

model), allows a third category of sites, which has an $\omega>1$. In the last two comparisons the neutral M7 model assumes that $\omega$ follows a beta distribution with 10 categories, each corresponding to a distinctive $\omega$ value that is always less than 1 while the also neutral M8a model, which is similar to the model M7, allows for an extra class of codons with $\omega=1$. The alternative model, M8, has an extra category with an $\omega>1$ (more details of the models can be found in Yang et al., 2000 and Yang et al., 2005). To assess whether allowing codons to evolve under positive selection gives a significantly better fit to the data, the log likelihood values for each pair of nested models were compared using a likelihood ratio test (LRT). The level of significance for these LRTs was performed using four degrees of freedom for the comparison between models M0-M3, two degrees of freedom in both comparisons between M1a-M2a and M7-M8 and one degree of freedom for the comparison M8a-M8. Simulations were run three times with multiple starting values for $\omega$. Finally, the empirical Bayes method (Nielsen and Yang, 1998; Wong et al., 2004) was used to determine which amino acids were most likely responsible for the signature of positive selection. Sites with posterior probabilities $>0.95$ were considered likely to have evolved under adaptive evolution. 
Table 2

Likelihood ratio statistics $(2 \Delta \mathrm{l})$ for comparison of different models of codon evolution at the major capsid gene VP60 of RHDV

\begin{tabular}{lrll}
\hline Comparison & $2 \Delta \mathrm{l}$ & d.f. $^{\text {a }}$ & Significance \\
\hline M0 (one ratio) vs. M3 (discrete) & 238.6 & 4 & $<0.001$ \\
M1a (nearly neutral) vs. M2a (selection) & 2.0 & 2 & $>0.05$ \\
M7 (beta) vs. M8 (beta and $\omega$ ) & 22.4 & 2 & $<0.001$ \\
M8a (beta and $\omega=1$ ) vs. M8 (beta and $\omega$ ) & 4.0 & 1 & $<0.05$
\end{tabular}

a Number of degrees of freedom used.

\section{Results and discussion}

Evidence for positive selection on RHDV VP60 sequences was detected using a ML method implemented in the software package PAML (Yang, 1997). We compared models that incorporate or prohibit positive selection (Table 2). We found that the comparisons M0 to M3, M7 to M8 and M8a to M8 are significant and models permitting positive selection are a better fit to the data (Table 2 , significance values in bold). The more conservative comparison, M1a to M2a was not significant. In addition, all models allowing for positive selection had a class of codons with $\omega$ values above 1.0. Therefore, we evaluated which amino acids are most likely responsible for the non-neutral pattern detected. Three codons appear to be under positive selection (posterior probabilities over 95\%; the results are presented in Table 3 according to the models tested). Positively selected codons (PSCs) were identified at three of the six regions of the VP60 protein (Table 4) with two of them in the hypervariable regions $\mathrm{C}$ and $\mathrm{E}$. The presence of PSCs within the $\mathrm{E}$ region is in accordance with indications that this region contains the main antigenic determinants (Capucci et al., 1995, 1998; Neill,
1992; Seal, 1994). Also, for Feline calicivirus (FCV), both the C and $\mathrm{E}$ regions of the capsid were found to be exposed to positive selection (Coyne et al., 2007). In addition, in Norwalk virus, another member of the Caliciviridae family, the P2 subdomain, which in RHDV show overlaps with the regions $\mathrm{C}$ and $\mathrm{E}$, was proposed to contain determinants for strain specificity (Prasad et al., 1999), while the blocking of the region between amino acid residues 300 and 384 inhibited the binding of the virus capsid to cells (White et al., 1996). The association between positive selection and antigenicity suggests an immune-mediated mechanism for RHDV evolution. The evidence of positive selection at other regions than the proposed to contain the antigenic determinants may indicate the existence of other antigenic determinants on the major capsid protein that stimulate protective immune responses. Especially the region $\mathrm{C}$ which is located on the surface of the capsid could be involved in interactions with host receptors.

Amino acid substitutions at the PSCs may impose changes in the polarity or charge of the protein (Table 4). The polarity and the charge of a protein are important for the protein structure and protein-protein interaction. Amino acid possibilities within the positively selected site 432 showed changes only with respect to charge, whereas the other positively selected amino acids are neutral, but showed changes with respect to polarity.

Changes at the three PSCs can generate a putative $\mathrm{N}$ glycosylation site (Table 4). On average, there are seven to nine $\mathrm{N}$-glycosylation sites found in VP60 of RHDV. N-linked glycosylation is one of the most common post-translational modifications in newly synthesised proteins and involves the attachment of a high mannose core to the amide nitrogen of an asparagines residue. $\mathrm{N}$ glycosylation allows viruses to increase surface diversity which is

Table 3

Summary of parameter estimates and likelihood values of different models of codon evolution for the major capsid gene VP60 of RHDV

\begin{tabular}{|c|c|c|c|}
\hline Nested model pairs & Log likelihood & Parameter estimates ${ }^{b, c}$ & Positively selected codons ${ }^{d}$ \\
\hline M0 (one ratio): $1^{\mathrm{a}}$ & -8043.7 & $\omega=0.09$ & None \\
\hline M3 (discrete): $5^{\mathrm{a}}$ & -7924.4 & $\begin{array}{l}p_{0}=0.90, p_{1}=0.09,\left(p_{2}=0.01\right) \\
\left(\omega_{0}=0.03\right),\left(\omega_{1}=0.50\right), \omega_{2}=\underline{1.88}\end{array}$ & Not allowed \\
\hline M1a (nearly neutral): $1^{\mathrm{a}}$ & -7929.7 & $\begin{array}{l}p_{0}=0.94,\left(p_{1}=0.06\right) \\
\left(\omega_{0}=0.04\right),\left(\omega_{1}=1\right)\end{array}$ & Not allowed \\
\hline M2a (positive selection): $3^{\mathrm{a}}$ & -7928.7 & $\begin{array}{l}p_{0}=0.94, p_{1}=0.05,\left(p_{2}=0.01\right) \\
\left(\omega_{0}=0.04\right),\left(\omega_{1}=1\right), \omega_{2}=\underline{2.39}\end{array}$ & $305,307, \mathbf{4 3 2}, 476$ \\
\hline M7 (beta): $2^{\mathrm{a}}$ & -7937.0 & $p=0.10, q=0.92$ & Not allowed \\
\hline M8a (beta and $\omega=1$ ) $3^{a}$ & -7927.8 & $p_{0}=0.95,\left(p_{1}=0.05\right) p=0.27, q=4.87(\omega=1)$ & Not allowed \\
\hline M8 (beta and $\omega$ ): $4^{\mathrm{a}}$ & -7925.8 & $p_{0}=0.98,\left(p_{1}=0.02\right) p=0.19, q=2.69, \omega=\underline{1.59}$ & $305,307,412,425, \mathbf{4 3 2}, \mathbf{4 7 6}, 572$ \\
\hline
\end{tabular}

Underlined numbers are evidence of positive selection

a Number of free parameters in the $\omega$ distribution.

b Values in parentheses are not free parameters.

c Parameters $p$ and $q$ are the shape parameters of the beta distribution which underlies M7 and M8.

d Codons inferred to be under selection at the $85 \%$ level. Numbers in bold refer to codons with posterior probabilities over $95 \%$.

Table 4

Characteristics of the amino acid possibilities at the positively selected codons (PSCs) with posterior probabilities $>95 \%$ (model M8)

\begin{tabular}{|c|c|c|c|c|c|}
\hline Position & Region & Amino acid possibilities & Polarity & Charge & Potential site of N-glycosylation \\
\hline 307 & $\mathrm{C}$ & $\begin{array}{l}\mathrm{S} \\
\mathrm{G} \\
\mathrm{N}\end{array}$ & $\begin{array}{l}\text { Hydrophilic } \\
\text { Hydrophobic } \\
\text { Hydrophilic }\end{array}$ & $\begin{array}{l}\text { Neutral } \\
\text { Neutral } \\
\text { Neutral }\end{array}$ & Yes \\
\hline 432 & $\mathrm{E}$ & $\begin{array}{l}\mathrm{S} \\
\mathrm{N} \\
\mathrm{K}\end{array}$ & $\begin{array}{l}\text { Hydrophilic } \\
\text { Hydrophilic } \\
\text { Hydrophilic }\end{array}$ & $\begin{array}{l}\text { Neutral } \\
\text { Neutral } \\
\text { Positive }\end{array}$ & Yes \\
\hline 476 & $\mathrm{~F}$ & $\begin{array}{l}\mathrm{A} \\
\mathrm{S} \\
\mathrm{T}\end{array}$ & $\begin{array}{l}\text { Hydrophobic } \\
\text { Hydrophilic } \\
\text { Hydrophilic }\end{array}$ & $\begin{array}{l}\text { Neutral } \\
\text { Neutral } \\
\text { Neutral }\end{array}$ & Yes \\
\hline
\end{tabular}


known to affect infectivity, protein folding, tropism, proteolytic processing and immune evasion (reviewed in Vigerust and Shepherd, 2007). Thus, alteration of a glycosylation site can affect virus survival and transmissibility. Several human viral pathogens including those causing AIDS, hepatitis, influenza and West Nile disease, take advantage of glycosylation to evade the host immune system and to increase virulence (reviewed in Vigerust and Shepherd, 2007). Site-directed mutagenic studies on other single-stranded positivesense RNA viruses revealed that the deletion of $\mathrm{N}$-glycosylation sites enhance the host immune response and decrease the virulence (e.g. Liu et al., 2007; Sainz et al., 2008). Drugs that inhibit viral $\mathrm{N}$-glycosylation of the virus envelope are currently being tested for preventing viral infection (e.g. Balzarini, 2007). One of the RHDV strains known to be non-pathogenic (RCV; GenBank accession number X96868; Capucci et al., 1996), differs from pathogenic strains by missing amino acids 307 and 308, which determine one of the predicted N-glycosylation sites. Position 307 was found to be under positive selection.

In conclusion, we provide evidence of positive selection at the major capsid protein VP60 of RHDV. The results suggest that PSCs tend to be associated with known antigenic regions, indicating that viral variation is mainly driven by the host immune response. Positively selected sites at other regions may indicate antigenic determinants yet to be discovered. Identifying these PSCs is important, as this variation is likely to be related to pathogenicity and virulence. However, virulence may be a multigenic trait with other regions of the genome, that may not stimulate directly protective immune responses, also determining virulence (by controlling replication rate, proteolytic activity, etc.).

\section{Acknowledgements}

This work was supported by the Foundation for Science and Technology Portugal: project POCTI/BIA-BDE/61553/2004 and grants SFRH/BPD/27021/2006, SFRH/BD/31048/2006, SFRH/BD/ 31093/2006, SFRH/BD/23786/2005 to P.J.E., J.A., A.M. and M.C., respectively.

\section{References}

Abrantes, J., Esteves, P.J., van der Loo, W., 2008. Evidence for recombination in the major capsid gene VP60 of the rabbit haemorrhagic disease virus (RHDV). Arch. Virol. 153, 329-335.

Balzarini, J., 2007. Targeting the glycans of glycoproteins: a novel paradigm for antiviral therapy. Nat. Rev. Microbiol. 5, 583-597.

Capucci, L., Fallacara, F., Grazioli, S., Lavazza, A., Pacciarini, M.L., Brocchi, E., 1998. A further step in the evolution of rabbit hemorrhagic disease virus: the appearance of the first consistent antigenic variant. Virus. Res. 58, 115-126.

Capucci, L., Frigoli, G., Rønshold, L., Lavazza, A., Brocchi, E., Rossi, C., 1995. Antigenicity of the rabbit hemorrhagic disease virus studied by its reactivity with monoclonal antibodies. Virus. Res. 37, 221-238.

Capucci, L., Fusi, P., Lavazza, A., Pacciarini, M.L., Rossi, C., 1996. Detection and preliminary characterization of a new rabbit calicivirus related to rabbit hemorrhagic disease virus but nonpathogenic. J. Virol. 70, 8614-8623.

Coyne, K.P., Gaskell, R.M., Dawson, S., Porter, C.J., Radford, A.D., 2007. Evolutionary mechanisms of persistence and diversification of a calicivirus within endemically infected natural host populations. J. Virol. 81, 1961-1971.

Ferreira, P.G., Costa-e-Silva, A., Monteiro, E., Oliveira, M.J.R., Aguas, A.P., 2004. Transient decrease in blood heterophils and sustained liver damage caused by calicivirus infection of young rabbits that are naturally resistant to rabbit haemorrhagic disease. Res. Vet. Sci. 76, 83-94.

Forrester, N.L., Abubakr, M.I., Abu Elzein, E.M.E., Al-Afaleq, A.I., Housawi, F.M.T., Moss, S.R., Turner, S.L., Gould, E.A., 2006. Phylogenetic analysis of rabbit haemorrhagic disease virus strains from the Arabian Peninsula: did RHDV emerge simultaneously in Europe and Asia? Virology 344, 277-282.
Forrester, N.L., Boag, B., Moss, S.R., Turner, S.L., Trout, R.C., White, P.J., Hudson, P.J., Gould, E.A., 2003. Long-term survival of New Zealand rabbit haemorrhagic disease virus RNA in wild rabbits, revealed by RT-PCR and phylogenetic analysis. J Gen. Virol. 84, 3079-3086.

Forrester, N.L., Trout, R.C., Gould, E.A., 2007. Benign circulation of rabbit haemorrhagic disease virus on Lambay Island, Eire. Virology 358, 18-22.

Forrester, N., Moss, S., Turner, S., Schirrmeier, H., Gould, E., 2008. Recombination in rabbit haemorrhagic disease virus: possible impact on evolution and epidemiology. Virology 376, 390-396.

Hall, T.A., 1999. BioEdit: a user-friendly biological sequence alignment editor and analysis program for Windows 95/98/NT. Nucleic Acids Symp. Ser. 41, 95-98.

Le Gall, G., Arnauld, C., Boilletot, E., Morisse, J.P., Rasschaert, D., 1998. Molecular epidemiology of rabbit haemorrhagic disease virus outbreaks in France during 1988 to 1995. J. Gen. Virol. 79 (Pt 1), 11-16.

Le Gall-Reculé, G., Zwingelstein, F., Laurent, S., de Boisséson, C., Portejoie, Y., Rasschaert, D., 2003. Phylogenetic analysis of rabbit haemorrhagic disease virus in France between 1993 and 2000, and the characterisation of RHDV antigenic variants. Arch. Virol. 148, 65-81.

Lemey, P., Derdelinckx, I., Rambaut, A., Van Laethem, K., Dumont, S., Vermeulen, S. Van Wijngaerden, E., Vandamme, A., 2005. Molecular footprint of drug-selective pressure in a human immunodeficiency virus transmission chain. J. Virol. 79, 11981-11989.

Liu, M., Chen, H., Luo, F., Li, P., Pan, Q., Xia, B., Qi, Z., Ho, W., Zhang, X., 2007. Deletion of $\mathrm{N}$-glycosylation sites of hepatitis $\mathrm{C}$ virus envelope protein $\mathrm{E} 1$ enhances specific cellular and humoral immune responses. Vaccine 25, 6572-6580.

Moss, S.R., Turner, S.L., Trout, R.C., White, P.J., Hudson, P.J., Desai, A., Armesto, M Forrester, N.L., Gould, E.A., 2002. Molecular epidemiology of rabbit haemorrhagic disease virus. J. Gen. Virol. 83, 2461-2467.

Neill, J.D., 1992. Nucleotide sequence of the capsid protein gene of two serotypes of San Miguel sea lion virus: identification of conserved and non-conserved amino acid sequences among calicivirus capsid proteins. Virus Res. 24, 211-222.

Nielsen, R., Yang, Z., 1998. Likelihood models for detecting positively selected amino acid sites and applications to the HIV-1 envelope gene. Genetics 148, 929-936.

Nowotny, N., Bascuñana, C.R., Ballagi-Pordány, A., Gavier-Widén, D., Uhlén, M., Belák, S., 1997. Phylogenetic analysis of rabbit haemorrhagic disease and European brown hare syndrome viruses by comparison of sequences from the capsid protein gene. Arch. Virol. 142, 657-673.

O’Keefe, J.S., Tempero, J.E., Motha, M.X.J., Hansen, M.F., Atkinsona, P.H., 1999. Serology of rabbit haemorrhagic disease virus in wild rabbits before and after release of the virus in New Zealand. Vet. Microbiol. 66, 29-40.

Parra, F., Prieto, M., 1990. Purification and characterization of a calicivirus as the causative agent of a lethal hemorrhagic disease in rabbits. J. Virol. 64, 4013-4015.

Prasad, B.V.V., Hardy, M.E., Dokland, T., Bella, J., Rossmann, M.G., Estes, M.K., 1999. $\mathrm{X}$-ray crystallographic structure of the Norwalk virus capsid. Science 286, 287-290.

Rodák, L., Smíd, B., Valícek, L., Veselý, T., Stĕpánek, J., Hampl, J., Jurák, E., 1990 Enzyme-linked immunosorbent assay of antibodies to rabbit haemorrhagic disease virus and determination of its major structural proteins. J. Gen. Virol. 71 (Pt 5), 1075-1080.

Ross, H.A., Rodrigo, A.G., 2002. Immune-mediated positive selection drives human immunodeficiency virus type 1 molecular variation and predicts disease duration. J. Virol. 76, 11715-11720.

Sainz, I.F., Holinka, L., Lu, Z., Risatti, G., Borca, M., 2008. Removal of a N-linked glycosylation site of classical swine fever virus strain Brescia Erns glycoprotein affects virulence in swine. Virology 370, 122-129.

Seal, B.S., 1994. Analysis of capsid protein gene variation among divergent isolates of feline calicivirus. Virus Res. 33, 39-53.

Thiel, H., Konig, M., 1999. Caliciviruses: an overview. Vet. Microbiol.V 69, 55-62.

Vigerust, D.J., Shepherd, V.L., 2007. Virus glycosylation: role in virulence and immune interactions. Trends Microbiol. 15, 211-218.

White, L.J., Ball, J.M., Hardy, M.E., Tanaka, T.N., Kitamoto, N., Estes, M.K., 1996. Attachment and entry of recombinant Norwalk virus capsids to cultured human and animal cell lines. J. Virol. 70, 6589-6597.

Wong, W.S.W., Yang, Z., Goldman, N., Nielsen, R., 2004. Accuracy and power of statistical methods for detecting adaptive evolution in protein coding sequences and for identifying positively selected sites. Genetics 168, 1041-1051.

Xu, Z.J., Chen, W.X., 1989. Viral haemorrhagic disease in rabbits: a review. Vet. Res. Commun. 13, 205-212.

Yang, Z., 1997. PAML: a program package for phylogenetic analysis by maximum likelihood. Comput. Appl. Biosci. 13, 555-556.

Yang, Z., Nielsen, R., Goldman, N., Pedersen, A.M., 2000. Codon-substitution models for heterogeneous selection pressure at amino acid sites. Genetics 155, 431-449.

Yang, Z., Wong, W.S., Nielsen, R., 2005. Bayes empirical bayes inference of amino acid sites under positive selection. Mol. Biol. Evol. 22, 1107-1118.

Zheng, T., Napier, A.M., Parkes, J.P., O'Keefe, J.S., Atkinson, P.H., 2002. Detection of RNA of rabbit haemorrhagic disease virus from New Zealand wild rabbits. Wildl. Res. 29, 683-688. 